\title{
Production and Application about TENNIS FLAT SERVE TEACHING SOFTWARE-Based on the High-Quality Goods Curriculum Platform
}

\author{
Weisong $\mathrm{Bu}$ \\ Jiangxi Normal University \\ Nanchang China 330022 \\ E-mail:185109230@qq.com
}

\author{
Kaiqiang Guo \\ Jiangxi Normal University \\ Nanchang China 330022 \\ E-mail:guokaiqiang2008@yeah.net
}

\begin{abstract}
Using CAI technologies to product the tennis flat serve teaching software. It relies on High-quality goods curriculum platform of Jiangxi normal university. It combines with tennis teaching and training theory to solve the key difficult problem in process of the tennis flat serve teaching. Main conclusions: 1), Design the tennis serve teaching software should follow the rules of tennis skills teaching and pay attention to the integration with Authorware7.0; 2), We should be pay attention to the editing of images and graphics When making flat serve teaching software, for interactive links the effectiveness and pertinence of teaching content; 3 ), The production of courseware must highlight student's main body status and increase the interactive courseware.
\end{abstract}

Keywords-Tennis flat serve; software production; software design

\section{INTRODUCTION}

A. Technical characteristics of tennis flat serve have great power, great threat and travels faster in tennis teaching process. It is important and difficult contents in tennis teaching practice.

B. Practice has proved that cannot achieve expected teaching goals only rely on the traditional teacher's explanation, demonstration and presentation in class. With the popularity of education informatization, using of computer multimedia technology and based on the tennis ball serve teaching characteristics

$C$. Now relying on the high quality course website of Jiangxi normal university to establish of tennis flat serve teaching platform, So as to enhance the interactivity of network teaching, help students establish correct concept of technology and master tennis flat serve technology. So as to optimize and improve the method of teaching tennis flat serve technology, and then to improve the teaching quality of tennis flat serve technology courses.

\section{MORAL SOFTWARE AND HARDWARE USED IN TEACHING SOFTWARE DEVELOPMENT}

A.It uses of a hardware device including that an Acer notebook and related supporting facilities, a video camera.

$B$. The teaching software based on Windows 7 systems. Using of Authorware7.0 to design a framework in the development of the teaching software. Editing and analysis of the image using the Dart fish motion analysis software,
Macromedia Flash 8 software, Corel Video Studio Pro X5 software and soon.

\section{Design ConcePt about the TenNis Flat SERVE TEACHING SOFTWARE}

A. Integrated the basic theoretical knowledge and practical the teaching knowledge of tennis flat serve. And according to the general basic characteristic of the special student tennis, using computer CAI technology teaching software to design and manufacture.

$B$. The demonstration operation design of teaching and learning: Clicking the corresponding presentation content to study through the mouse. The specific composition includes that text presentation teaching and video presentation teaching.

C. Software production must to be simple and clear, friendly interface, convenient operation. Do simple text box design, control button using time accurate, It can invoke the related content at any time and can satisfy the double main body the guiding ideology of teaching and learning.

$D$. There are three kinds of teaching software's application forms and the main is high-quality goods curriculum network platform to enhance the teaching interaction.(Fig.1)

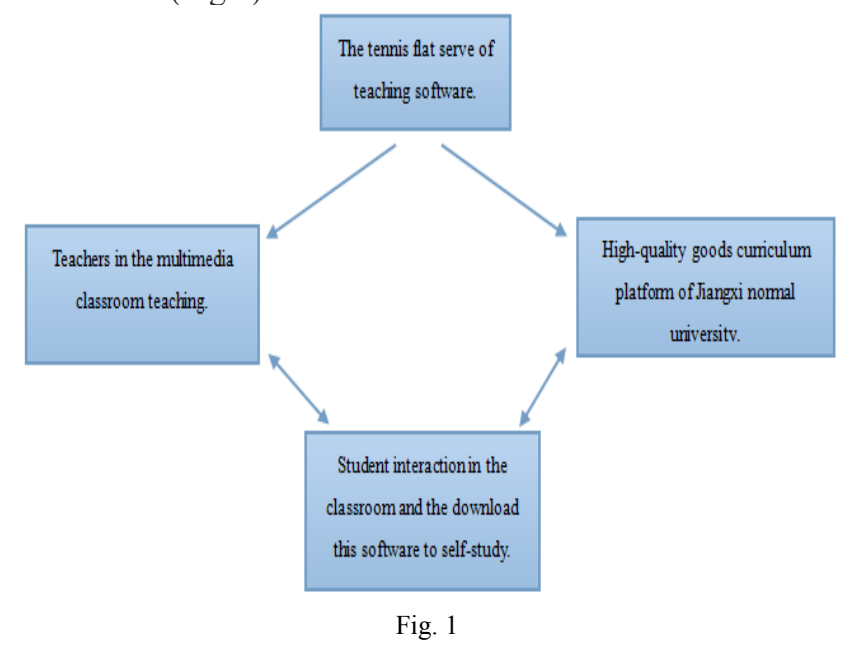


IV. The Tennis Flat Serve Teaching Software DESIGN PROCESS ANALYSIS

A. The tennis flat serves teaching software of the method

(1) Using Authorware7.0 version to realize that making the teaching software is.

(2) Arrange and collect the multimedia materials to Editing and analysis using the Dart fish motion analysis software, Macromedia Flash 8 software, Corel Video Studio Pro X5 software and so on.

(3) Design the teaching program flow and establishing interactive mechanism (Fig. 2) ;

(4) Add the topic background, inset audio video and text in the software; To beautify and optimization software;

(5) To inspection and test of software, release after testing software running normally;

(6) Upload the software to Tennis teaching courseware column of high-quality goods curriculum website of Jiangxi normal university.

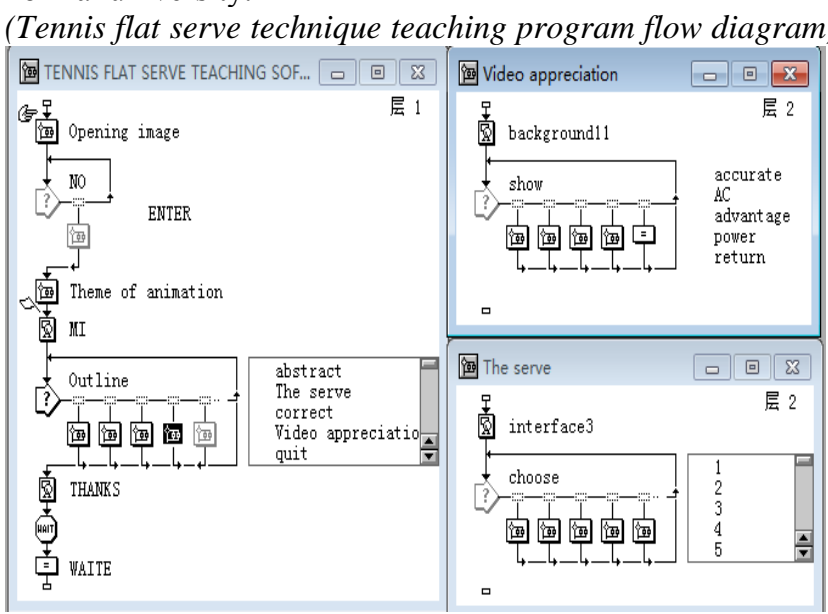

Fig.2

B. The content framework tennis of tennis flat serve teaching software

According to the theory of Tennis teaching method and the characteristic of the flat serve technology, the teaching software of content brought tennis flat serve is divided into four parts:

1) The characteristics of tennis flat serve, 2 ) The main technical points action of tennis flat serve、3) The common mistake and corresponding correction method of tennis flat serve 、4) Wonderful tennis flat serve.

The first part from grip, characteristics and power order to introduced tennis flat serve (Fig.3).

The second part makes a detailed analysis of the main technical points of tennis flat serve. It is divided into seven parts : Ready position of tennis flat serve; Backswing of tennis flat serve; Throw the ball hit the ball position of tennis flat serve; The body movements before hit the ball; The arm movements before hit the ball;After tennis flat serve landing action; Angle degrees bones show more about tennis flat serve. (Fig.4)

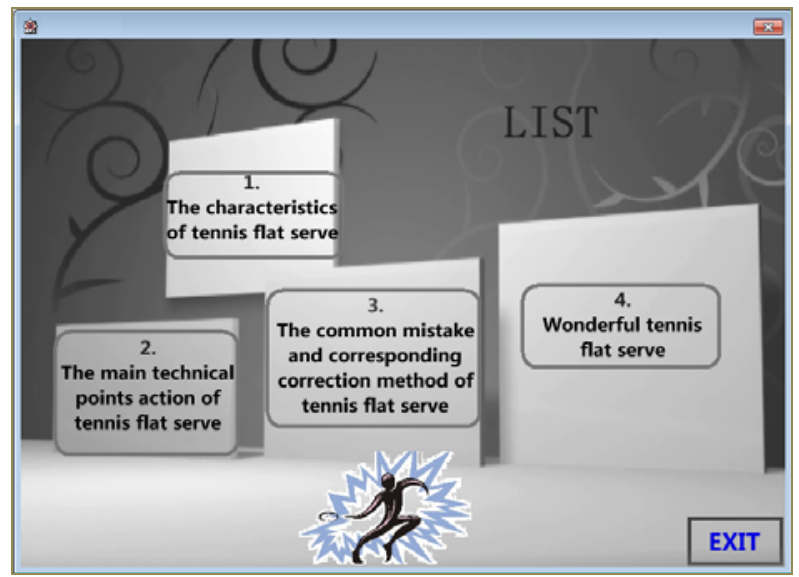

Fig.3

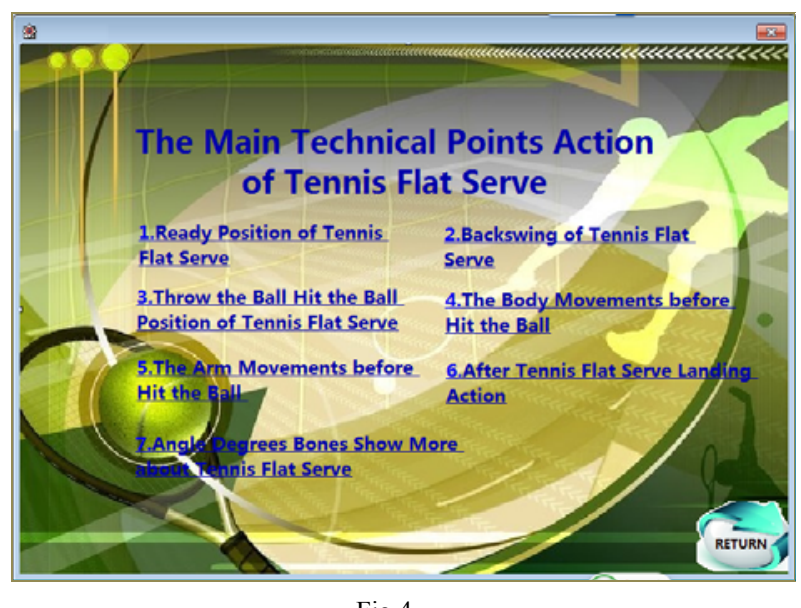

Fig.4

The third part is the easy to make mistakes and correct method in the practice of flat serve. Summarizes the 6 point defect on the flat serve exercise and put forward the correction methods (Fig.5).

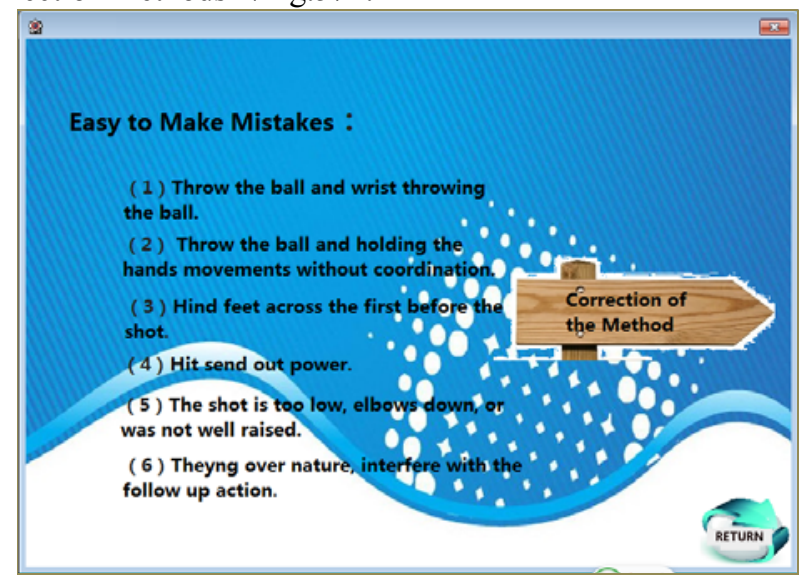

Fig.5 
The fourth part is the wonderful tennis flat serve appreciation. This section makes reference to the wonderful flat firing ball in recent years, respectively to show tennis flat serve from four aspects :the flat serve's precision, ACE, serve power and tennis flat serve's advantage (Fig.6)

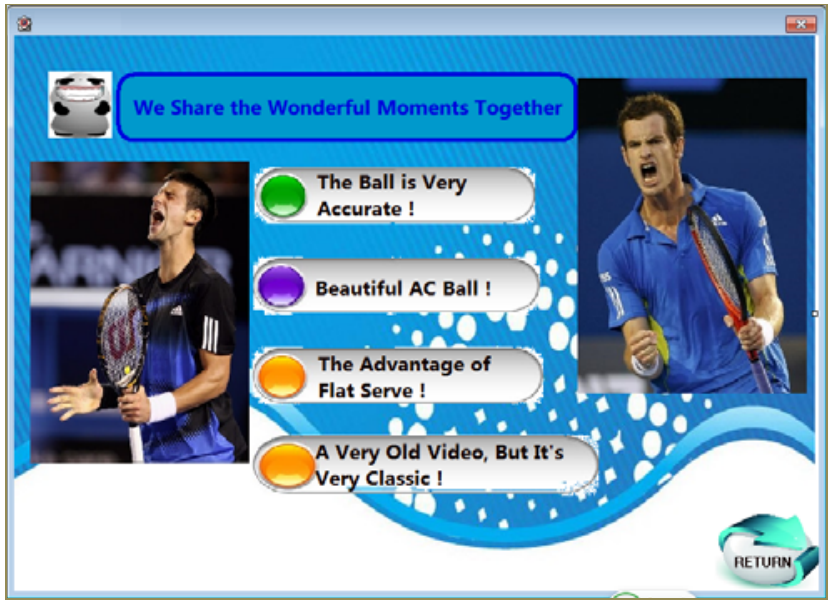

Fig.6

\section{The application methods of teaching software about Tennis flat serve}

The flow diagram of the teaching software is shown in figure 7. Open the package $\rightarrow$ double click "The multimedia teaching software of tennis flat serve technology" main program (If you are equipped with the 360 software e.g. Will occur "remind" dialog, Please allow the program running) $\rightarrow$ To start the animation and click on the "ENTER" to the main page $\rightarrow$ Click on the corresponding contents to study tennis flatten serve.

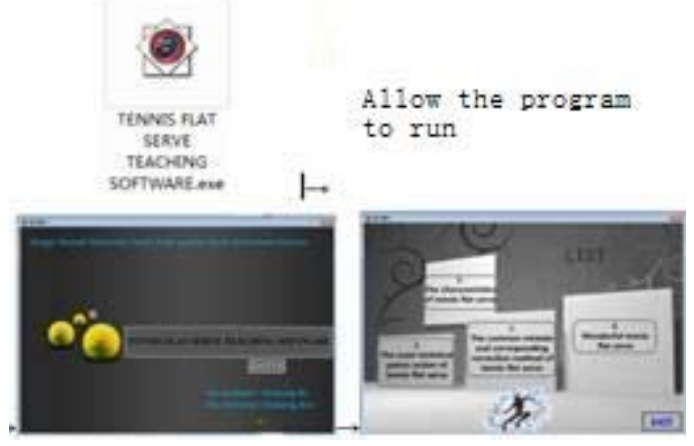

Fig.7

D. The application value of teaching software about Tennis
flat serves
Based on network platform, reasonable arrangement, clearer teaching goal and stronger interactivity, it's has a popularization application value to the nation's college tennis teaching. Not only can improve students' level of tennis flat to fire the ball but also create conditions for students' self-study and provides service space. More major is: Application of the CAI software for teaching methods to innovate and change, it also can promptly and effectively to solve practical problems, then promote the development of tennis teaching in colleges and universities effectively.

\section{CONCLUSION}

Teaching software settings and application during the network platform need to follow the modern education thought and sports education theory. In this way we can do very reasonable to making the teaching design, the navigation strategy design, the system structure model design and the interactive surface design e.g. Also in the practice of teaching should emphasize the integration of teaching objectives and teaching content. In the process of teaching, we can use modern education technology to solve to solve the crucial and difficult problem in tennis flat serve. In this way, we can let students to grasp the inner nature of tennis flat serve technology, which fully reflects the flat serve strength, speed and attack the technical features with good effect. We should be repeated in future using this software at the same time, according to the feedback of software to modification, complement and innovation constantly, so as to develop multimedia teaching software which obeys the law of sports teaching skills.

\section{ACKNOWLEDGMENT}

Thanks for the guidance of Professor Kaiqiang Guo. The project supported by the Jiangxi Normal University Graduate Students Innovation Fund Program in 2013.

\section{REFERENCES}

[1] Kaiqiang Guo , CAI teaching`s design and development of the skill of tennis serving [J].World Academic Union 2009 (5).

[2] Kaiqiang Guo. CAI courseware design of baseball and softball [J].IEEE Catalog 2012 (8)

[3] Kaiqiang Guo. College sports professional teachers technical exquisite course network teaching design is discussed [J].MelbourneAustralia, 2010 (12)

[4] Kaiqiang Guo. Research progress of computer image graphics technology in sports training in 2008 (C) Journal of Communication and Computer, USA Vol. ISBN: 978, No.0-9798471-03 PP96-98. (2009).

[5] Kaioliang Guo. CAI design of the featured courses for PE major', M\&D Forum,Vol, Dec. 2010, pp. 140-143.

[6] Kaiqiang Guo. The volleyball's frontal spiking technique development of CAI teaching designing [J]. Journal of Beijing University of physical education ,2004 (9)

[7] Kaiqiang Guo., CAI teaching design and development for referee scoring of table tennis-a case of tennis excellent courses of Jiangxi Normal University, IEEE Catalog Number: CFP1153K-PRT , ISBN: 978-1-61284-772-6 PP2993-2997,2011. 